\title{
Comparison of air-purification characteristics for potted Golden Hahnii and Warneckii
}

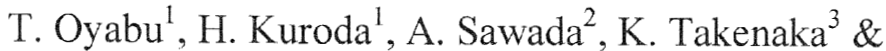 \\ B.C. Wolverton ${ }^{4}$ \\ 'Post Graduate School of Regional Economic Systems, Kanazawa Seiryo \\ University, Japan. \\ ${ }^{2}$ Japan Advanced Institute of Science and Technology, Japan. \\ ${ }^{3}$ Takenaka Garden Afforestation Co. Ltd., Japan. \\ ${ }^{4}$ Wolverton Environmental Services Inc., USA.
}

\begin{abstract}
Golden Hahnii and Warneckii are two kinds of small foliage plants that have a healing effect on humans. These potted plants also have the capability to purify not only air pollution but also soil and water pollution. In this paper, the air purification capability is examined using a tin oxide gas sensor. The resistivity of the sensor decreased in polluting gases, which are kinds of reducing gases. As for the results these potted plants have a high capability to formaldehyde, xylene and toluene. Warneckii had a higher capability than that of Golden Hahnii. Golden Hahnii is one of the succulent plants and its capability is lower than nonsucculent plants. It is, however, obvious that the capability becomes higher at night even if the intensity of light is low. Most of the stomata open at night and take in carbon dioxide, and the plant organ produces a malic acid. Consequently, it is thought that the plant has a higher purification capability in darkness. A purified indoor air environment can be created in both the night and day, when the succulent and non-succulent plants are installed together.
\end{abstract}

\section{Introduction}

Airtight and high heat-resistant buildings have been provided to economize various kinds of energy. Many types of air polluting chemicals are generated in an indoor environment for this reason. And diseases such as sick building syndrome are caused even if in single domicile. Northern Europe and the USA 


\section{Environmental Health Risk}

regulated mainly the indoor concentration of formaldehyde, toluene and xylene, and tried to decrease their concentration about twenty years ago. Many research papers on the syndrome have been published in those countries. The regulated concentrations for these chemicals were also adopted a few years ago in Japan. As a result, the concentrations of those chemicals are decreasing now but they are still at a high level. There is no fundamental method to fix this problem even at this point.

The authors have investigated the air purification capability of pothos[1]-[2]. It is one of the familiar foliage plants and has a high capability to reduce those concentrations. The relationships among the grade of capability, soil kinds, room temperature and light intensity were examined and published in detail.

In this study, Warneckii ( Dracaena deremensis 'Warneckii') and Golden Hahnii (Sansevieria trifasciata 'Golden Hahnii') were adopted as the subjects and those capabilities were investigated. Golden Hahnii is one of the succulent plants. The mechanism of the purification process in plant organs has not been sufficiently made clear. It is considered that plants take in the pollutants through the stomata and decompose those substances[3]. Usually, the stoma opens in the daytime and closes in the nighttime. On the other hand, the stoma of succulent plants opens in the nighttime and closes in the daytime. The function is contrary with non-succulent plants. Consequently, Warneckii and Golden Hahnii were selected, and their capabilities for formaldehyde were examined in darkness and under light. These plants were also exposed to toluene and xylene. Toluene and xylene have a larger molecular weight than formaldehyde and it takes a longer term to purify these chemicals using plants.

\section{Experimental}

The experimental room temperature was controlled at about 22 degrees $\mathrm{C}$ by an air-conditioner, and the experimental chamber, which was about 300 litters $(575 * 510 * 1000 \mathrm{~mm})$, was placed in the room. A subjective foliage plant was placed in the chamber to investigate the air purification capability of the plant. The sun light was shielded in the room and the light intensity was controlled using fluorescent lightings. It is about 1000 lux near the plant leaves. The experimental system is shown in Fig.1. An air-polluting chemical is injected into the chamber using a micro-syringe and the plant air-purification capability is examined. The atmospheric concentration of the pollutant in the chamber was detected using a tin oxide gas sensor (Figaro, TGS\#826). The photograph of the sensor is shown in Fig.2. A load resistance was connected in series to the sensor and the voltage of both ends of the resistance was derived as the sensor output. When the output voltage is high, the concentration is high. After the injection of the pollutant, the sensor output immediately reaches a maximum voltage and it gradually decreases due to the plant purification-capability. Finally, it returns to the original level (base level) which is the level just before the injection. The voltage which is the maximum level from the base level is indicated as the symbol $h$, and the time until which the output reaches to the half level of $h$ is also indicated as the symbol $t_{w}$. The purification capability $\left(P_{a}\right)$ is expressed using $h$ 
Chamber

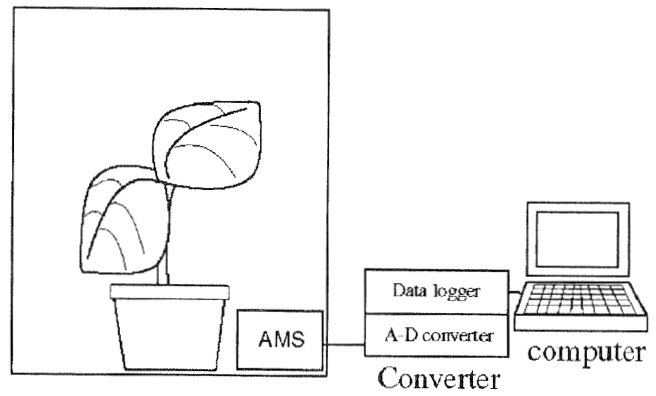

Figure 1: Measurement system of plant purification-ability for an indoor airpollutant.

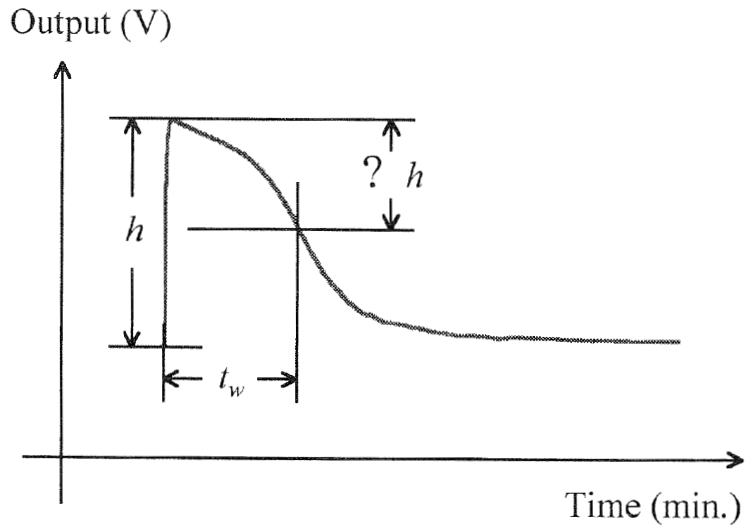

Figure 3: Meaning of the parameters, $h$ and $t_{w}$.

and $t_{w}[4]$, namely it is defined as eq.(1). Capability has not been indicated using a numerical value until now. Many kinds of advantages for humans can be derived if the capability of each plant can be indicated using a numerical value and the value is especially effective to maintain the purification of an indoor environment using plants. The derivation of $P_{a}$ is shown in Fig.3.

$$
P_{a}=h / t_{w} * 10
$$

The photographs of the subjective plants are shown in Fig.4. These plants are Warneckii and Golden Hahnii. The specific forms, habitats and growing temperature of these plants are indicated in Table 1. Golden Hahnii is one of succulent plants and a kind of Sansevieria. The plant is growing in a pot of which the diameter is $16 \mathrm{~cm}$ and height is also $16 \mathrm{~cm}$. The height of the plant is $13 \mathrm{~cm}$. Warneckii is growing in a pot of which the diameter is $19 \mathrm{~cm}$ and the height is $16 \mathrm{~cm}$. The height of the Warneckii is about $23 \mathrm{~cm}$. There are four pots in which two types of soils are charged, namely the mixed soil and the ordinary cultivated soil. The mixed soil is composed of red clay, peat moss, perlite and vermiculite. We labeled the mixed soil as Eco and the cultivated soil as Ordinal. 


\section{Environmental Health Risk}

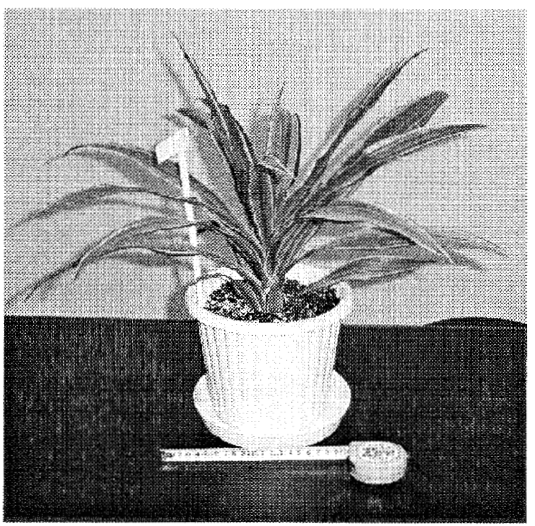

(a) Warneckii

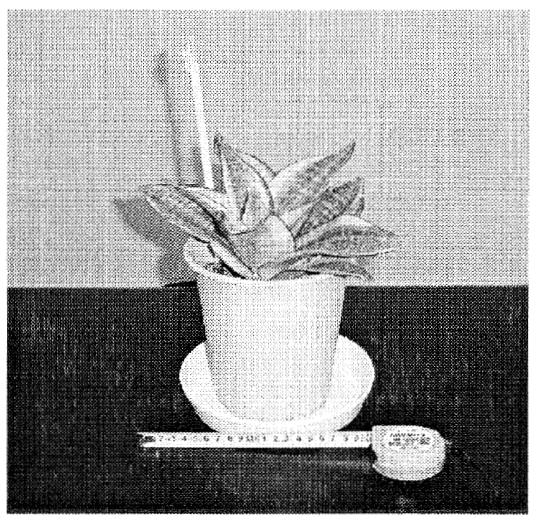

(b) Golden Hahnii

Figure 4: Warneckii and Golden Hahnii adopted in this experiment.

Table 1: The specific forms, the habitats and growing temperature of the examined plants.

Scientific name

Dracaena deremensis

'Warneckii'

Sansevieria trifasciata

'Golden Hahnii'
Specific form

Habitat

Growing

temperature $(\mathrm{C})$

\section{Results}

\subsection{Sensor characteristics}

The relationship between $h$ and the concentrations of the three kinds of pollutants is indicated in Fig.5. $h$ is the value from the base level to the maximum level of the sensor output. The characteristics have almost a linear relationship. The adopted sensor had a higher sensitivity to xylene and toluene than formaldehyde, and the value of $h$ is large for the chemicals. Very small amounts of the pollutants are immediately adsorbed on the chamber wall and plant leaves after the injection of the subjective pollutants but the volume is negligible. In this experiment, it is about several percents of the injected volume. 


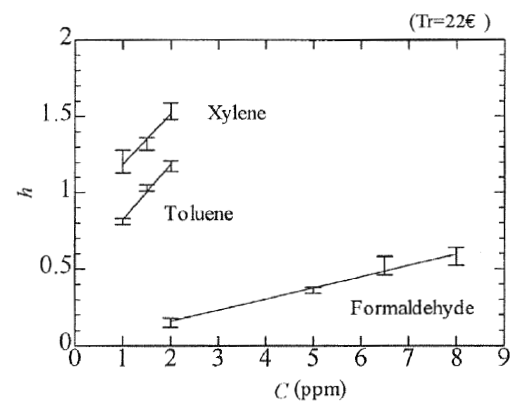

Figure 5: Peak $h$ of sensor output as a function of the concentrations of three chemical substances which cause sick-building syndrome.

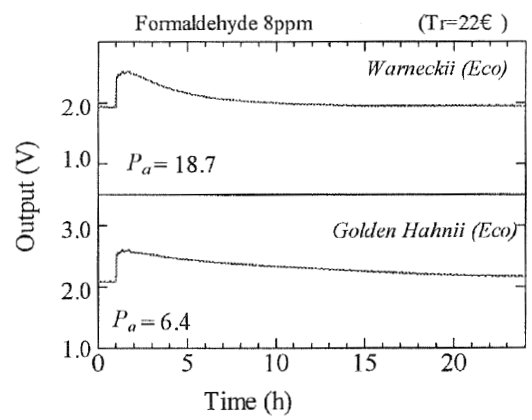

Figure 6: Purification characteristics of Warneckii and Golden Hahnii for $8 \mathrm{ppm}$ of formaldehyde.

The purification characteristics of Warneckii and Golden Hahnii, which are each growing in Eco soil pots respectively are shown in Fig.6. In the figure, formaldehyde was injected into the chamber to the concentration of $8 \mathrm{ppm}$. The purification capabilities of these plants were 18.7 and 6.4 respectively. Warneckii had the higher capability. It was about 2.0 in the control experiment when no plant was placed in the chamber. Golden Hahnii has a purification capability but it is low. The purification capability of the Warneckii that was growing in the Ordinal soil was also examined for toluene at the concentration of 1.5ppm. The result is shown in Fig.7. The capability was 6.3 and it took a long period than the formaldehyde to purify the pollutant. The characteristics for xylene under the same conditions are also indicated in Fig.8. It is very similar to the case of toluene. $P_{a}$ was 7.9 . It took about 48 hours until the polluting level returned to the base level in both experiments. Warneckii has a constant capability even if the polluting level changed, namely $P_{\alpha}$ characteristic does not depend on the concentration of xylene and toluene. It is important to derive the number of plant pots to purify the indoor environment.

The molecular weight of formaldehyde is about 30, for toluene 92 and for xylene it is 106 . The purification capability of pothos for various kinds of air 
64 Environmental Health Risk

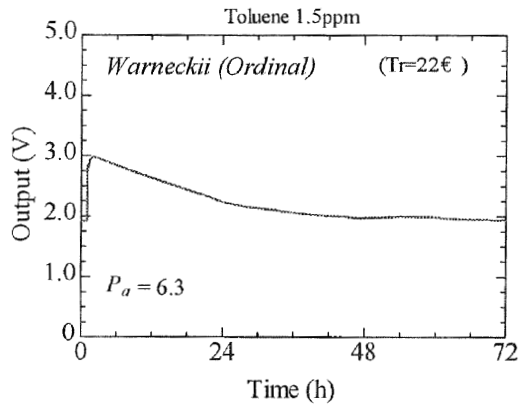

Figure 7: Purification characteristics of Warneckii for $1.5 \mathrm{ppm}$ of Toluene.

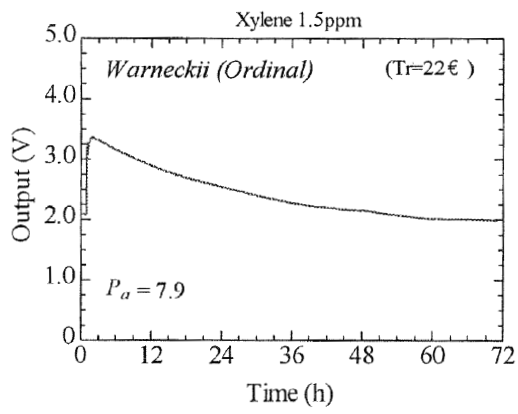

Figure 8: Purification characteristics of Warneckii for $1.5 \mathrm{ppm}$ of xylene.

polluting chemicals became higher as the molecular weight of the chemical became smaller in our previous study[4]. The above mentioned results are the same as this study.

\subsection{Purification capability of Warneckii}

The purification capabilities of Warneckii for formaldehyde growing in the two kinds of soils (Eco and Ordinal) are indicated in Fig.9 as a function of formaldehyde concentration. The relationship between $P_{a}$ and formaldehyde concentration $(C \mathrm{ppm})$ under a light of 1000 lux can be expressed using an approximate function. The functions were derived using the least-square approximate method. They are shown in eq.(2) and (3). Eq.(2) is for Eco soil and (3) is for Ordinal soil. There is not a large difference among these soils. There is the tendency that $P_{a}$ becomes higher as the formaldehyde concentration becomes higher under light. The $P_{a}$ s for 5 and $8 p p m$ in darkness are also indicated in Fig.9. $P_{a}$ becomes lower in darkness than under light. The adopted Warneckii was comparatively a small type of which the height was $23 \mathrm{~cm}$ from the soil surface. It, however, had a high capability under light.

Pa-eco $=2.17 \mathrm{C}+1.63$ 


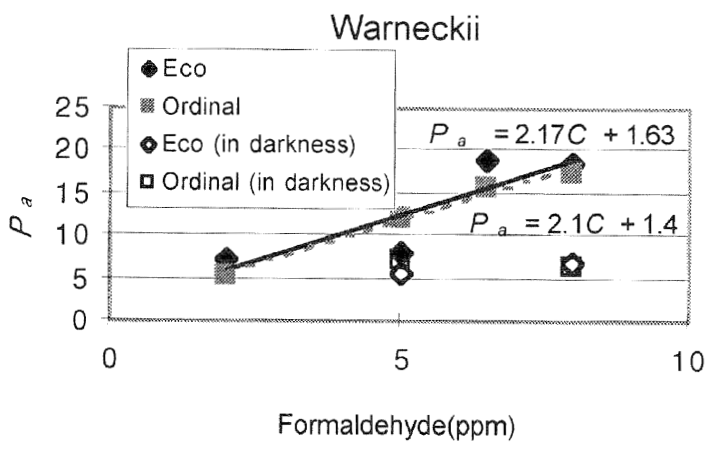

Figure 9: Purification capability of Warneckii as a function of formaldehyde concentration.

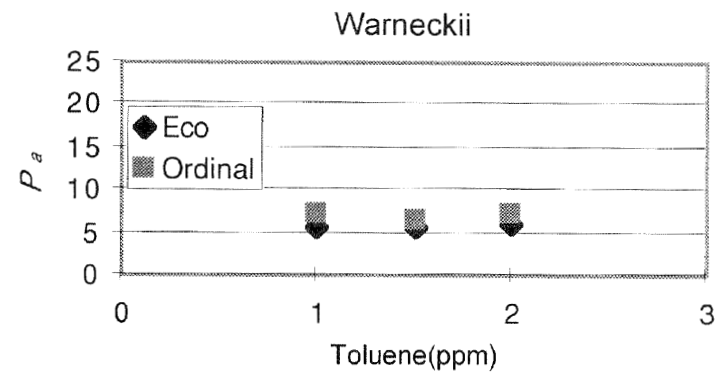

Figure 10: Purification capability of Warneckii as a function of toluene concentration.

Pa-ord $=2.1 \mathrm{C}+1.4$

The $P_{a}$ s of Warneckii for the three concentrations of toluene were also examined. The results are shown in Fig. 10. The $P_{a}$ characteristics were just about constant in the examined concentration range and the values were 5.6 to 7.3 . The characteristics for xylene are also shown in Fig.11. The range of $P_{a}$ was 6.1 to 8.8. It is very similar to toluene. There was no difference among the soil types.

\subsection{Purification capability of Golden Hahnii}

The $P_{a}$ characteristics of Golden Hahnii for formaldehyde concentration are indicated in Fig.12. The purification characteristics were examined at four formaldehyde concentrations. The concrete values were 4.05, 6.0, 7.7, and 5.6 at the concentrations of $2,5,6.5$ and $8 \mathrm{ppm}$. The standard deviation of the values is 1.34. $P_{a}$ values of Golden Hahnii for formaldehyde concentrations of 5 and $8 \mathrm{ppm}$ in darkness were almost equal and also there was no difference for soil-type. The 
66 Environmental Health Risk

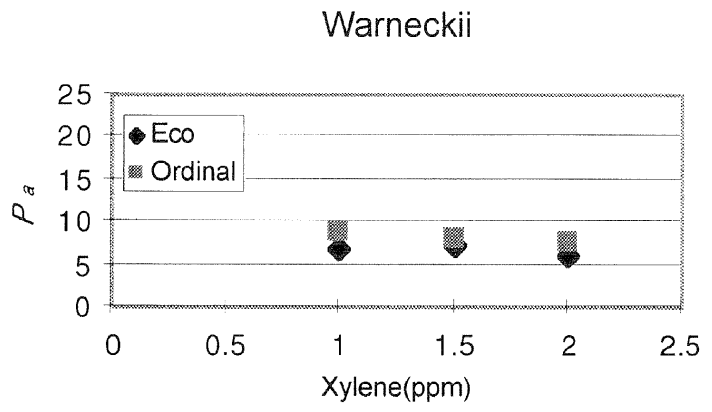

Figure 11: Purification capability of Warneckii as a function of xylene concentration.

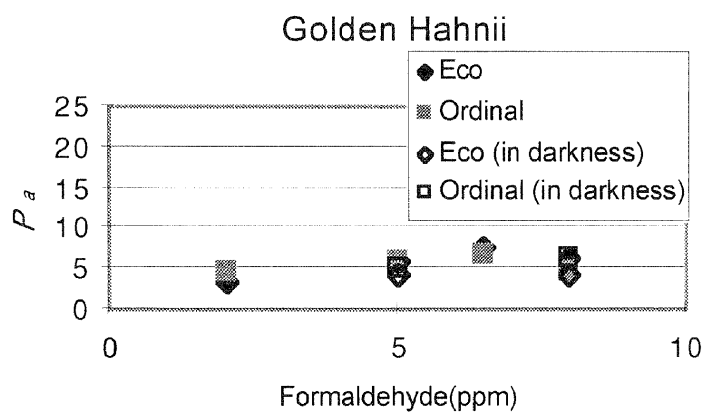

Figure 12: Purification capability of Golden Hahnii as a function of formaldehyde concentration.

average $P_{a}$ values were 4.7 and 5.3. Those were almost the same in the case of under light.

A pair of Golden Hahnii was growing in a larger pot, whose size was $22 \mathrm{~cm}$ in diameter and $24 \mathrm{~cm}$ in height. They were the same size and same kind with the one in Fig.4. The purification capability of the pot for a formaldehyde concentration of $8 \mathrm{ppm}$ was examined and the capabilities under light were 10.3 in Eco soil and 12.2 in Ordinal soil. In darkness, their values were 10 and 11.7. The purification capability of Golden Hahnii does not vary whether under light or in darkness. The capability of a pair of Golden Hahnii was twice as large as one plant. The capability of Warneckii in darkness was lower than under light. Golden Hahnii, however, had the same capability even in darkness. In a previous study, it became obvious that the purification capability of pothos became higher as the light intensity became higher. It, however, saturated over 1000 lux and was low in darkness[5]. Stomata open and close periodically, namely they open 
in the daytime and close in the nighttime. A succulent plant such as Golden Hahnii has the reverse function. The stomata of the plant open in the nighttime and take in carbon dioxide and volatile organic compounds (VOCs). The plant converts $\mathrm{CO}_{2}$ to malic acid. Golden Hahnii continuously has the same purification capability even in nighttime.

The purification capability of the ordinal plant is higher in the daytime but lower in the nighttime. It is desirable to maintain the purifying of air pollution in an indoor environment. It is better to adopt both succulent and non-succulent plants to keep a clean atmosphere. Carbon dioxide and VOCs in a room are absorbed the whole day by those plants. It is also important for various kinds of plants to be placed in an indoor environment from the view of design. Especially, humans desire to spend time in a safe and clean air environment.

\subsection{Purification capability of Cyclamen}

Cyclamen persicum which was in some small flowers was also adopted as a subject. It had healing effects for humans. The purification capability of the cyclamen was also examined. The purification characteristic for formaldehyde of 20ppm is shown in Fig.13. The results of Eco and Ordinal soils are shown in (a) and (b). $P_{a}$ was 13.7 in the case of Eco soil and 11.4 in the case of Ordinal soil. The cyclamen which was growing in the Eco soil pot had a somewhat higher capability than that of Ordinal soil. There was not a difference among Eco and Ordinal soils in the Warneckii and Golden Hahnii experiments. In the cyclamen experiment, it was recognized that there was a significant difference. Plants have a symbiosis relation with microbes in the rhizosphere. It is necessary to offer the proper soil environment where plants and the microbes can interact comfortably. This is essential for the plant to have a high air-purification capability.

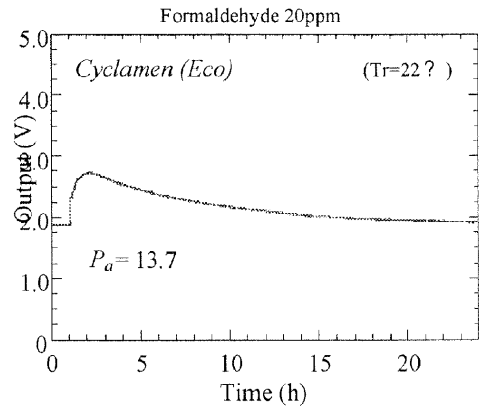

(a) Eco

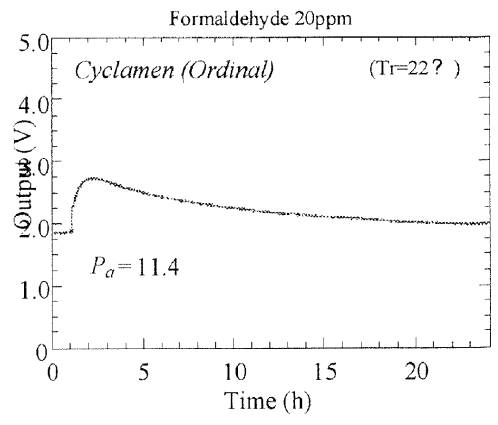

(b) Ordinal

Figure 13: Purification characteristics of Cyclamen for $20 \mathrm{ppm}$ of Formaldehyde. 


\section{Environmental Health Risk}

\section{Conclusions}

The air-purification capability of Warneckii and Golden Hahnii were examined using a tin oxide gas sensor. Cyclamen with some small flowers was also adopted as a subject and the capability was examined as a reference. It is very pretty and has healing effects for people. The opening and closing of the plant stomata has a daily fluctuation. These open in the daytime and close in the nighttime. The succulent plant, however, has the reverse characteristic, namely most of the stomata open in the nighttime and close in the daytime. Warneckii and Golden Hahnii were adopted as the subjects and their air-purification capabilities were examined. Golden Hahnii is one of the succulent plants. And cyclamen was also adopted as the typical foliage plant with flowers in winter. Formaldehyde, toluene and xylene were used as the air polluting chemicals. The molecular weights of toluene and xylene are large. Warneckii had a higher purification capability for these three chemicals. Golden Hahnii had a lower capability for formaldehyde but it kept up the capability even in the nighttime. Namely, the plant had the capability for the whole day. A clean indoor environment can be kept all day by using the succulent and non-succulent plants. The plants contribute greatly to humans for maintaining a purified indoor environment. We can maintain a high purifying indoor environment by using these various kinds of plants and flowers which can also have healing effects by looking at them. We must continuously have a symbiosis relationship with plants.

Hereafter, the influences of light intensity to the air purification capability of succulent plants will be studied and the design effects by planting various plants together will be also studied.

\section{References}

[1] Takashi Oyabu, Ayako Sawada, Takeshi Onodera, Kozaburo Takenaka, Bill Wolverton, Characteristics of potted plants for removing offensive odors. Sensors \& Actuators B, 89, pp.131-136, 2003.

[2] Takashi Oyabu, Takeshi Onodera, Ayako Sawada, Kozaburo Takenaka, Purification Capability of Potted Plants for Removing Atmospheric Formaldehyde. Electrochemistry, 71(6), pp.463-467, 2003.

[3] K.Omasa, H.Saji, S.Youssefian, N.Kondo, Air Pollution and Plant Biotechnology, Springer: Tokyo and New York, 2002.

[4] Takashi OYABU, Takeshi ONODERA, Haruhiko KIMURA, Yoshihiko SADAOKA, Purification Ability of Interior Plant for Removing of IndoorAir Polluting Chemicals Using a Tin Oxide Gas Sensor. Journal of Japan Society for Atmospheric Environment, 36(6), pp.319-325, 2001.

[5] Takeshi Onodera, Shigeki Hirobayashi, Haruhiko Kimura, Takashi Oyabu, Purification Rate for Epipremunum aureum for Formaldehyde in Light. Trans. of IEE Japan, 119-E(11), pp.532-537, 1999. (in Japanese) 